\title{
Statistical design of Phase II/III clinical trials for testing therapeutic interventions in COVID-19 patients
}

Shesh N. Rai ${ }^{1,2^{*}+}$ (D) Chen Qian ${ }^{1,2 \dagger}$, Jianmin Pan ${ }^{1}$, Anand Seth ${ }^{3}$, Deo Kumar Srivastava ${ }^{4}$ and Aruni Bhatnagar ${ }^{5^{*}}$

\begin{abstract}
Background: Because of unknown features of the COVID-19 and the complexity of the population affected, standard clinical trial designs on treatments may not be optimal in such patients. We propose two independent clinical trials designs based on careful grouping of patient and outcome measures.

Methods: Using the World Health Organization ordinal scale on patient status, we classify treatable patients (Stages 3-7) into two risk groups. Patients in Stages 3,4 and 5 are categorized as the intermediate-risk group, while patients in Stages 6 and 7 are categorized as the high-risk group. To ensure that an intervention, if deemed efficacious, is promptly made available to vulnerable patients, we propose a group sequential design incorporating four factors stratification, two interim analyses, and a toxicity monitoring rule for the intermediate-risk group. The primary response variable (binary variable) is based on the proportion of patients discharged from hospital by the $15^{\text {th }}$ day. The goal is to detect a significant improvement in this response rate. For the high-risk group, we propose a group sequential design incorporating three factors stratification, and two interim analyses, with no toxicity monitoring. The primary response variable for this design is 30 day mortality, with the goal of detecting a meaningful reduction in mortality rate.
\end{abstract}

Results: Required sample size and toxicity boundaries are calculated for each scenario. Sample size requirements for designs with interim analyses are marginally greater than ones without. In addition, for both the intermediaterisk group and the high-risk group, the required sample size with two interim analyses is almost identical to analyses with just one interim analysis.

Conclusions: We recommend using a binary outcome with composite endpoints for patients in Stage 3, 4 or 5 with a power of $90 \%$ to detect an improvement of $20 \%$ in the response rate, and a 30 day mortality rate outcome for those in Stage 6 or 7 with a power of 90\% to detect 15\% (effect size) reduction in mortality rate. For the intermediate-risk group, two interim analyses for efficacy evaluation along with toxicity monitoring are encouraged. For the high-risk group, two interim analyses without toxicity monitoring is advised.

Keywords: Composite outcomes, COVID-19, Efficacy, Hospitalization, Interim analysis, Intubation, Power, Mortality, Sample size, Toxicity monitoring

\footnotetext{
*Correspondence: shesh.rai@louisville.edu; aruni.bhatnagar@louisville.edu

'Shesh N. Rai and Chen Qian contributed equally to this work.

'Biostatistics and Bioinformatics Facility, James Graham Brown Cancer Center, University of Louisville, Louisville, KY 40202, USA

${ }^{5}$ Department of Medicine, Christina Lee Brown Envirome Institute, University of Louisville, Louisville, KY 40202, USA

Full list of author information is available at the end of the article
}

(c) The Author(s). 2020 Open Access This article is licensed under a Creative Commons Attribution 4.0 International License, which permits use, sharing, adaptation, distribution and reproduction in any medium or format, as long as you give appropriate credit to the original author(s) and the source, provide a link to the Creative Commons licence, and indicate if changes were made. The images or other third party material in this article are included in the article's Creative Commons licence, unless indicated otherwise in a credit line to the material. If material is not included in the article's Creative Commons licence and your intended use is not permitted by statutory regulation or exceeds the permitted use, you will need to obtain permission directly from the copyright holder. To view a copy of this licence, visit http://creativecommons.org/licenses/by/4.0/. The Creative Commons Public Domain Dedication waiver (http://creativecommons.org/publicdomain/zero/1.0/) applies to the data made available in this article, unless otherwise stated in a credit line to the data. 


\section{Background}

\section{Challenges in COVID-19 clinical trials design}

The ongoing COVID-19 (SARS-COV-2 infection) crisis is an unprecedented public health challenge as there are no clinically-proven interventions with substantial evidence that can effectively manage the infection. To meet this challenge, researchers around the world have been working diligently on developing new treatment plans or drugs. Several clinical interventions including those that involve the use of convalescent plasma, a combination of existing drugs, or repurposed drugs, have either entered the clinical trial phase or completed small size studies (a partial list of drugs/therapies used for COVID-19 treatment is given in the appendix). In a recently published preliminary report, Remdesivir was deemed to be a better treatment drug in terms of shortening the time to recovery in adults hospitalized with COVID-19, but this drug had previously failed in a relatively smaller trial [1, 2]. In general, COVID-19 research has been criticized for being non-rigorous [3] and many clinical trials have shown uncertain results due to various reasons, including missing or inappropriate control group, small sample size and/or rigorous statistical designs [4-8]. Hydroxyquinone, for example, found to be effective in a small clinical trial [9] failed to show efficacy in a larger trial [10]. Likewise, the trial on Lopinavir-Ritonavir in adults with COVID-19 concluded that "future trials in patients with severe illness may help to confirm or exclude the possibility of a treatment benefit" [8].

Key reasons for the failure of approaches attempted so far are the uniqueness and the range of the population affected by COVID-19 compared with clinical trials with other populations, as well as the speed at which such trials must be conducted. Clearly, there is urgent need for conducting well-designed and wellpowered clinical evaluation of potential COVID-19 therapies. However, with patients showing up with a variety of characteristics and fast changing status, it is difficult to recruit and conduct an appropriate trial that could best show the effectiveness of an intervention. Many factors, such as patient status, age, sex, race, co-morbidity, etc., can affect the design or the outcome of the trial and therefore these features must be taken into consideration as stratification factors in designing a well-powered study. Moreover, because of rapid changes in infection rates in a particular location, there is only a limited window of opportunity to conduct single-site clinical trials [11]. Therefore, a wide set of such factors, and a rapidly changing patient population, make it challenging to develop a design that minimizes the imbalance in treatment allocation with respect to stratification factors, while ensuring that the number of strata remain manageable.

\section{World Health Organization ordinal scale}

The World Health Organization has established an ordinal scale system to best describe the clinical status of a patient [12]. A similar 7-category ordinal scale has been used in a previous trial [8]. This scale has proven to be an effective in describing the severity of illness as well as in assessing clinical outcomes in hospitalized patients. This 7-category ordinal scale has been used recently by Wang et al., [13] to categorize outcomes in patients hospitalized with seasonal influenza infection. The authors found the scale to be a useful in capturing a broad range of clinical states as well as in tracking a patient's status change. Although the ordinal scale is useful for patient classification, but because of differing responses it is not efficient to design a trial based on every stage. Also, patients at different stages of the disease require different treatment. Therefore, we combined groups with potentially similar responses and treatment methods together. The details of this World Health Organization ordinal scale are given in Table 1 . Stage 0 is not included here because the uninfected population is not of interest in the context of a clinical trial.

\section{Composite endpoints}

A composite endpoint is a single measure of effect, based on a combination of individual components endpoints. Composite endpoints have high utility in evaluating the efficacy of therapeutic interventions that could individually or concurrently alter several different symptoms or outcomes. For example, in Type II diabetics, a drug may affect HbA1C (hemoglobin A1C), body weight, and systolic blood pressure [14]. Often, the frequency of events in individual components of a composite endpoint may be low, so several components are combined to assess the overall efficacy of an intervention. However, each component of a composite endpoint should be clinically meaningful. Ideally, all component should be weighted equally, but this is rarely possible, therefore the relative importance of the components may have to be determined by the frequency of occurrence of the component outcomes. For instance, in cardiovascular trials - death, myocardial infarction (MI), stroke, coronary revascularization and hospitalization for angina are commonly combined, although fatal and non-fatal events are not be treated as the same. In a recent study, patients and clinical trial authors, when asked to assign "spending weights" to five events - death, myocardial infarction, stroke, coronary revascularization and hospitalization for angina, assigned different weights to each of these components [15].

In trials where death is a possible outcome, it is often included as a part of a composite outcome to capture the overall efficacy of the treatment. In this regard, the 
statistical theory of competing risk supports the inclusion mortality as a component of a composite outcome [16]. In a review of 14 journals between January 2000 to January 2007, of the 1231 cardiovascular trials, 37\% used composite endpoints, and $98 \%$ of these trials included mortality as a component [17].

In our study design, we selected the $15^{\text {th }}$ day to determine the patient's status because the 14-day period is the mean duration for patient recovery, or a complete cycle of treatment, as shown in Cao et al. [8]. A 14 day follow up has been used in other studies as well [10]. The estimated mean duration of hospital stay among survivors in the US is 9.3 days (with $95 \%$ staying 0.8 to 32.9 days) and among non-survivors was 12.7 days (1.6 to 37.7 days) [18]. Likewise, systemic review of 52 studies, showed that the median length of stay in China was 10-19 days, and 5 (interquartile range: 3-9) outside China [19]. Therefore, a 14-day follow-up is likely to be sufficient for evaluating efficacy. Other useful values (median days) adopted from Cao's manuscript are:

Time to Clinical Improvement -.-.-.-.---16 Days

Intensive Care Unit (ICU) Length of Stay------10 Days

Duration of Invasive Mechanical Ventilation (IMV)-5 Days

Days on Oxygen Support-............-...-13 Days

Length of Hospitalization--.---.--.---.----15 Days

The WHO has proposed time to clinical improvement as the primary endpoint in the R\&D blueprint report [12]. The "time to clinical improvement" is defined by Cao [8] as the time from randomization to either an improvement of two points on a 7-category ordinal scale or discharge from the hospital, whichever comes first. However, based on conversations with more than 50 frontline physicians, we believe that the WHO endpoint may not be the best choice. The reason is that the authors do not feel that in the intermediate-risk group the time it takes for a patient to be cured, whether it is 15 days or 18 days, is important. What is of greater interest is acceptable recovery from the infection ('full cure'), therefore, we propose a binary

Table 1 Different Stages of a Patient

\begin{tabular}{ll}
\hline Different Stages of a Patient \\
\hline 8 & Condition \\
7 & Death \\
6 & Ventilation with Additional Organ Support $\left(E C M O^{a}\right)$ \\
5 & Intubation and Mechanical Ventilation \\
4 & Non-invasive Ventilation or High-flow Oxygen \\
3 & Oxygen by Mask or Nasal Prongs \\
2 & Hospitalized; No Oxygen Therapy \\
1 & Limitation of Activities \\
\hline
\end{tabular}

${ }^{\mathrm{a} E C M O}$ Extracorporeal membrane oxygenation outcome to be the endpoint (whether the patient is cured after 14 days or not). The intent is identify the increase in response rate in the intermediate group with new treatment compared with standard care. The duration to evaluate the efficacy in the high-risk group is short, and there is no censoring, and no loss to follow-up. In the high-risk group, the most important outcome is survival. Therefore, we chose 30 day mortality as the primary outcome and do not suggest using a time-to-event approach for designing the trial.

The endpoints used in other published studies are: time to providing a nasopharyngeal swab negative RT-PCR for SARS-CoV-2 [6], incidence of either laboratory-confirmed COVID-19 or illness compatible with COVID-19 within 14 days [10], reduction in mortality by at least $50 \%$ in the high-dose group compared with the low-dose group [5], presence or absence of virus at day 6 [4], all-cause mortality at hospital discharge or at 60 days, and the WHO clinical progression scale [20].

Core Outcome Measures in Effectiveness Trials (COMET) initiative started on May 20-21 ${ }^{\text {st }}, 2015$ in Calgary, Alberta, Canada. Since then many efforts are underway to develop Core Outcome Set (COS) for various indications including COVID-19 [21, 22]. For COVID-19 disease prevention, efforts are underway to develop COS and for in hospitalized patients with confirmed or suspected COVID-19. Jin et al. have developed COS for mild (time to 2019-nCOV reverse transcription polymerase chain reaction (RT-PCR) negativity), ordinary type (length of hospital stay, severe type (composite events, length of hospital stay, $\mathrm{PAO} 2 / \mathrm{FiO} 2$, duration of mechanical ventilation and time to 2019-nCoV negativity), critical type (all-cause mortality) and rehabilitation (pulmonary function) [22]. The WHO group on COS in COVID-19 categorized COS outcome into three categories: Viral burden (PCR or nasopharyngeal swab), survival (Allcause mortality at hospital discharge or at 60 days) and clinical progression - WHO clinical progression scale measured daily over the course of the study [20]. Hospital discharge and mortality are both part of COS for COVID-19. Hospital discharge is around 15 days [23, 24]. The endpoint we have proposed are in line with the COMET initiative.

The purpose of this article is to propose effective statistical designs for COVID-19 clinical trials. Two parallel clinical trials design with respect to different patient risk groups are described. Issues and limitations are discussed. Required sample size in each arm under different scenarios along with toxicity boundaries are calculated and presented in a tabular form for ease of implementation and to inform clinical trial designs. 


\section{Methods}

This section contains two subsections, including one design for the intermediate-risk group and the other for the high-risk group.

A flowchart that illustrates the overall design of both such trials is shown in Fig. 1.

In our designs, the WHO ordinal scale is used to classify COVID-19 patients into different stages based on their clinical status, but it is difficult to design a trial based on every stage. As a result, we combined groups with similar standard treatment options together. Based on the ordinal scale, patients are separated into three group: High-Risk Group (Stages 6 and 7), IntermediateRisk Group (Stages 3, 4, and 5), Low-Risk Group (Stages 1 and 2). Patients in intermediate-risk group are treated in a similar way, while the high-risk group patients need more innovative and aggressive treatment. Two independent clinical trials with two different designs are proposed for the intermediate-risk group and the high-risk group. Note that if a patient in the intermediate-risk group could not recover and progresses to the high-risk group, then that patient could be eligible for the highrisk group trial.

We discuss considerations and provide specific justification for five important components when designing both clinical trials, including the outcome of the design, stratification, interim analysis, group ratio, and toxicity monitoring. In addition, futility stopping rules are also considered in both designs since there is no need to spend extra resource and energy if the drug is not effective.

\section{Design for Intermediate -risk group Outcome variables}

Since a larger number of patients are expected in the intermediate-risk group, it is feasible to use binary endpoints (success or failure).

We define $Y$ as the primary response variable based on the proportion of patients discharged from hospital by the $15^{\text {th }}$ day. Let $Y=1$ indicate the success outcome if the patient is discharged from the hospital by the $15^{\text {th }}$ day. Let $Y=0$ indicate the failure if the patient is not discharged from the hospital by the $15^{\text {th }}$ day, transiting to a higher WHO scale, or dead. Here, the failure is a composite endpoint. It is the similar logic adopted from the cardiovascular trials mentioned in the background section. In our case, $Y=1$ is the success with probability $P$ and $Y=0$ is the failure with probability 1-P. Accordingly, we calculated results based on the improvement of response rate from $40 \%$ in the standard arm to various rates $(50 \%, 55 \%, 60 \%, 65 \%, 70 \%, 75 \%, 80 \%)$ in the treatment arm.

Some secondary outcome variables might also be considered. For example, the change in viral load or biomarkers of inflammation such as ferritin or IL-6, time to reduced viral load, or the number of event-free days in the hospital (event-free survival).

\section{Stratification}

For ethical reason, group sequential designs are recommended in the current setting. Since many factors could impact the outcome, stratified randomization is more suitable. For doing so, Zelen's blocked randomization scheme with random block size (randomly selected size 4 or 6) is suggested [25]. In previous work Srivastava et al. [26] found that, with several factors appearing to affect the primary outcome of interest with their true distributions being unknown, or the possibility of causing heterogeneous treatment response among individuals in a group with unknown effect size, stratified randomization approach offered consistently better results if the effect size can be assumed to be marginally similar within each stratum.

Factors, such as age, race, sex, co-morbidity and viral load, which might impact the primary outcomes could be addressed by stratification. However, choosing the right factor for stratification is critically important. Many different issues need to be considered when choosing stratification factors. Based on the current clinical experience showing a strong dependence of COVID-19 outcomes on age, sex and diabetes, obesity and hypertension [27, 28], we consider four such factors for the intermediate-risk group: patient stage, at least one cardiovascular disease risk factor among obesity, hypertension and diabetes (Yes/No), age ( $<60$ and $\geq 60$ years), and sex (Male/Female).

For the intermediate risk group, we further classified patients in the three stages, those in Stages 3 and 4 and those in Stage 5 (essentially classifying patients into those who are not in ICU vs. those who are in ICU) and grouping them into two groups. This is suggested to minimize the number of strata for randomization while ensuring that patients within each stratum are relatively homogenous. All these factors are readily identifiable; however, for defining metabolic syndrome status, it may be necessary to include other factors that are representative of a patient's health condition. Alternatively, composite risk scores such as the Framingham, Reynolds, or GRACE risk scores may be used. Data to calculate cardiovascular risk score and/or obesity may be readily available, as patients are usually weighed and their blood pressure, cholesterol status, and diabetes are often known upon hospital admission. Although age is usually included in risk factor score, it could also be considered as a separate variable when the risk score cannot be calculated. Assuming that no risk scores are available, in our recommended design, we define two age groups: less than 60 years of age and greater than or equal to 60 years 


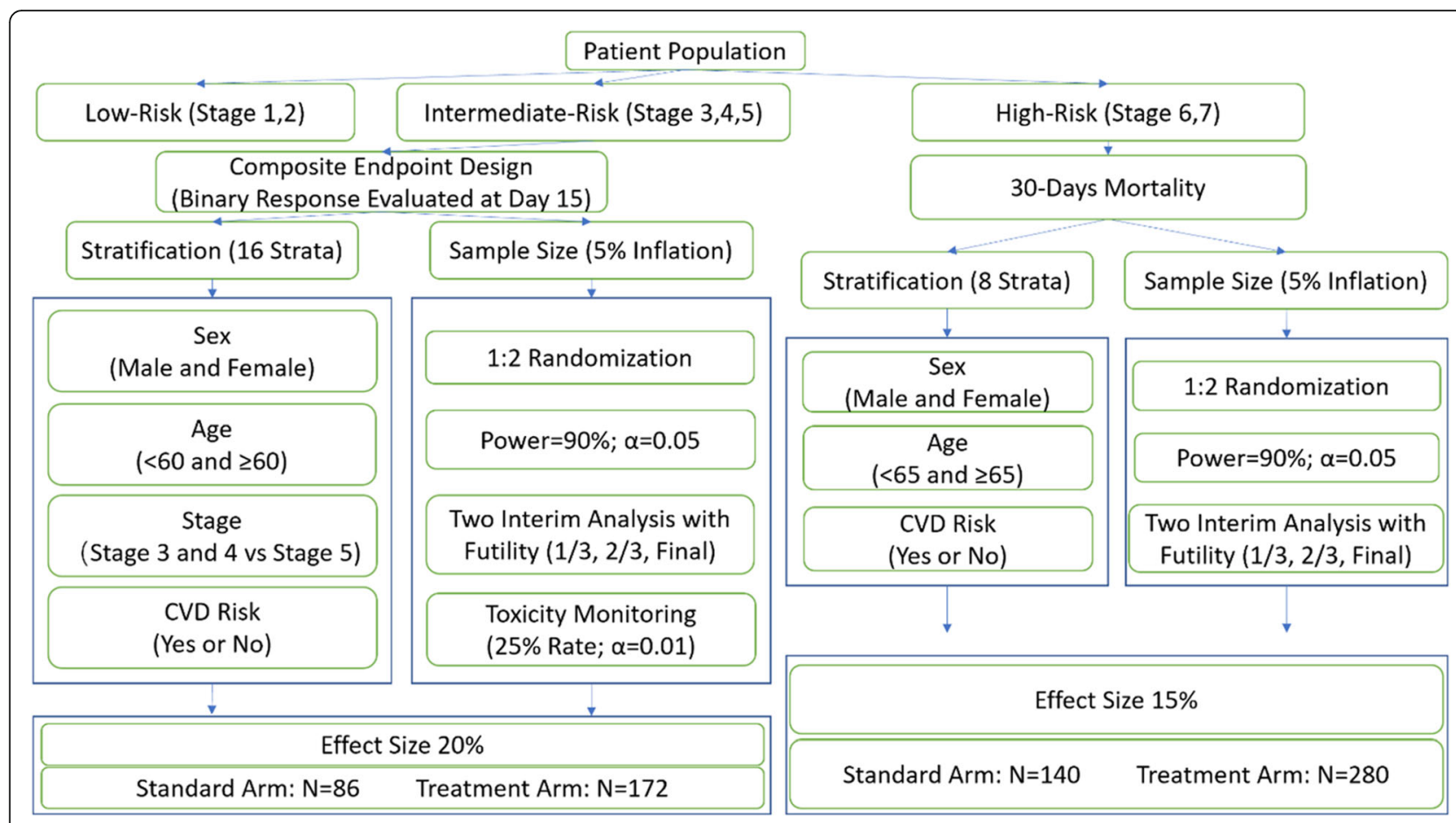

Fig. 1 Flowchart of Two Parallel Clinical Trials with Key Design Components

of age. It is generally known that patients in the intermediate-risk group are mostly elderly. Patients less than 50 years of age only count a very small percent of the patients admitted to a hospital. Therefore, the cutoff line at 60 years of age is selected to have balanced strata. Moreover, in view of studies showing that the recovery rate for males is lower than of females [29], sex should also be considered. With these four factors for stratification, there would be a total of 16 strata in the design, which makes the trial design somewhat manageable. Race is not explicitly considered, as there is no indication yet of race-dependent variations in outcome, independent of pre-existing disease burden.

\section{Interim analysis}

For the intermediate-risk group, two interim analyses are recommended. Results are presented for no interim analysis, one interim analysis and two interim analyses. We describe design parameters at alpha $=0.05$ and power $=90 \%$. Because the virus is life threatening, it is important to ascertain the efficacy of the intervention as early as possible and make the drug available to this patient population as soon as possible. Without interim analysis, researchers would know the outcome of the trials only after all patients have been enrolled. If one choose to perform one interim analysis, when $50 \%$ of patients are enrolled, then using G-rho spending function with rho equals 2 , one would stop the trial at the interim evaluation if the $p$-value of the test for comparing the two groups is less than 0.006 [30, 31]. Additionally, for futility evaluation, trial would also be stopped if the $\mathrm{p}$ value is greater than 0.716 . Otherwise, the trial should continue, and the final analysis will be conducted, and the efficacy of the treatment should be declared only if when the p-value is less than 0.047 . However, due to the insidious nature of this infection, waiting until $50 \%$ of patients enrolled to find out the result may still not be aggressive enough. Therefore, to fast track the process and to ensure that the drug can be made available to those who need it urgently, we recommend two interim analyses, with first interim analysis to be performed when one-third of total patient population has been enrolled and evaluated (effective new treatment if $p<$ 0.002 ) with futility look at $p>0.830$; second look being performed when two-third of the patients are enrolled and evaluated (effective treatment if $p<0.014$ ) with futility look at $p>0.298$; and the final analysis when all patients are enrolled $(p<0.046)$. Rho equals three is used in the G-rho spending function [30,31]. The choice of Rho was based on the consideration that we need to make the drug available to the patients quickly but we need to make sure that the trial is stopped early only if we have strong evidence that the drug is effective. This is the reason why we chose the $p$-values cut-offs at interim evaluations to be somewhat conservative (making sure that there is strong evidence in favor of the drug and avoid false positive findings). To explain with an example, assume the overall sample size is 243 in which 81 
belongs to the standard care arm and the rest 162 belongs to the treatment arm. At the first interim analysis, we have 54 patients (one third of 162). If $p<0.002$, then there is strong evidence to declare that the intervention is working, and the trial should stop right away. With this design, researchers can find out early whether the intervention works, or stop, if it is causing unacceptable harm to patients by monitoring toxicities. Considering some unforeseen reasons (e.g., patients change their mind regarding the study after randomization) the sample size should be increased by approximately $5 \%$ with resulting total $n=256$. If the expected effect is somewhat smaller (such as $10 \%$ ), the sample size will drastically increase $(n=978)$, however, the monitoring rule for efficacy and futility evaluations remains the same.

\section{Group ratio}

We calculate here sample sizes for both $1: 1$ and 1:2 randomizations for the intermediate-risk group. However, patients enrolled in treatment arm may be the same or twice the number of patients enrolled in the standard treatment arm. The choice of group ratio depends on the efficacy of the intervention in the pilot studies. If it is a new intervention that has not been approved by the FDA, then 1:1 randomization with block size of 4 is recommended in consideration of patient safety. If it is an approved procedure or drug with some preliminary data on efficacy with known toxicity profile, then 1:2 randomization with block size of 6 is recommended to ensure that if the drug is effective more patients get the advantage of being treated on the more efficacious arm.

\section{Toxicity monitoring}

Toxicity monitoring is challenging, but necessary. For the intermediate-risk group, a toxicity rate of $25 \%$ is recommended due to the urgent need of drugs for treatment. In other words, if intervention provides even minimal improvement, then it should still be considered as there is currently no known drug that is $100 \%$ effective against COVID-19. Also note that patient may die during the treatment due to other causes. We recommend monitoring for those toxicities (Common Terminology Criteria for Adverse Events (CTCAE) Grades > 2) that are related, possibly related and probably related to the drug, evaluated by the Data and Safety Monitoring Board (DSMB) [32].

\section{Design for High -risk group Outcome variables}

The number of patients in the high-risk group at each health care facility is likely to be small. Using time-tosurvival as an endpoint may not be ideal because the follow-up is short, and it may require a long time to enroll all patients and there would hardly be any right censoring. In other words, very few patients will survive pass the outcome evaluation time, thereby making time-to-survival as an endpoint ineffective. Therefore, in our design we focused on reducing 30 day mortality rate. Note that since there is no censoring and the length of follow-up is very short in this risk group, there is almost no difference between the choices of survival or binary endpoints [33].

We define the 30 days mortality as the primary outcome. Let $Y=1$ indicate death of patient within 30 days (failure), and $Y=0$ represents a person still alive on the 30th day (success). Accordingly, we calculated results based on the reduction of mortality rate from $80 \%$ or $70 \%$ in the standard arm to various rates $(70 \%, 65 \%$, $60 \%, 55 \%, 50 \%, 45 \%, 40 \%, 35 \%)$ in the treatment arm.

\section{Stratification}

For the high-risk group, stratification is recommended as sample size is satisfied when using 30 day mortality as primary outcome. Enrolling sufficient patients within a given timeframe should not be an issue assuming the trial is a multi-center trial.

For stratification, similar factors as discussed for the intermediate-risk group design are recommended, with some modification. We consider three factors for the high-risk group: one cardiovascular disease risk factors, such as diabetes, hypertension, and obesity (Yes/No), age $(<65$ and $\geq 65$ years), and sex (male/female). With these three factors for stratification, there would be a total of 8 strata in the design. The reason of selecting 65 years age as a cutoff point is that in a recent study of COVID19 , mortality rate for those who received mechanical ventilation in the age of 18 to 65 years was $76.4 \%$, and for those over 65 years of age, the mortality rate was 97.2\% [34]. Zelen's blocked randomization scheme with random block size (randomly chose size 4 or 6 ) is recommended in this risk group [25].

In the high-risk group, we did not further classify patients based on their stages (Stage 6 and 7) as we have done in the intermediate-risk group. The reason is that the number of patients in stage 7 is likely to be small, and it is not possible to stratify based on these two stages. However, technically it is ideal to stratify patients evenly in every arm based on their stages, but that is not achievable in this case. Since we have chosen other factors for stratification, if extreme bias occurs, then stage 7 patients should be dropped, and researchers should only perform analysis on stage 6 patients with $80 \%$ power.

\section{Interim analysis}

For the high-risk group, two interim analyses along with monitoring for efficacy and futility at overall alpha $=0.05$ and power $=90 \%$ are recommended. The reason is that 
the mortality rate in these patients is high and they need some innovative treatments. For example, convalescent plasma therapy has been widely attempted among the high-risk group. However, the levels of neutralizing antibodies in specific plasma preparation are likely to vary, leading to variable outcomes. Therefore, if during two interim analyses patients respond better to plasma with specific antibody titers, then the rest of the patients could be moved to the higher quality plasma quickly, so they have a higher chance of survival. In this design, first interim analysis is to be performed when one-third of total patient population has been enrolled, completed 30 days, and evaluated (effective new treatment if $p<$ 0.002 ) with futility look at $p>0.830$; second look being performed when two-third of the patients are enrolled, completed 30 days, and evaluated $(p<0.014)$ with futility look at $p>0.298$; and the final analysis when all patients are enrolled and completed 30 days $(p<0.046)$. Rho equals three is used in the G-rho spending function based on the consideration of being more conservative in interim analyses to ensure that the treatment is efficacious and avoid the chances of falsely declaring the treatment to be efficacious, which could mean heavy losses in terms of resources invested and loss of lives. Sample sizes for one interim analysis are also calculated and are given in Tables 8 and 9 in the appendix for reference.

\section{Group ratio}

For patients in the high-risk group, 1:2 randomization is recommended, because such patients are in danger and possibly have failed other treatments. Hence, they should be treated with whatever intervention available to improve their chances of survival. In addition, sample size is large enough to handle the 1:2 treatment allocation ratio when expecting a reduction of mortality rate from $70 \%$ to $55 \%$. Estimated sample sizes for $1: 1$ randomization are also calculated and provided in the appendix for reference.

\section{Toxicity monitoring}

For the high-risk group, no toxicity monitoring is necessary since mortality rate (between $70 \%$ and 97\%) has been reported across many health care facilities. With such a high death rate, it is not necessary to look at the toxicity level. Any reasonable intervention that could increase the chances of saving a patient should be attempted, regardless of treatable toxicities. In addition, two interim analyses are built in our design to help stop the trial early if any harmful events are detected.

\section{Results \\ Result for intermediate-risk group Sample size calculation}

In the intermediate-risk group, we assume the baseline success rate is $40 \%$ in the standard arm (Standard Care) and increased success rate in the treatment group. This estimate is based on a study showing that $38 \%$ patients requiring mechanical ventilation were discharged alive [34]. However, these data are from New York during the most severe phase of the outbreak. The baseline success in this group may be higher and therefore the study design could be modified accordingly. It may also be noted that assuming a baseline response rate of $40 \%$ provides a conservative estimate of the samples size and to detect the same effect size (for example, 20\%) the power would be enhanced if the baseline response rate is lower than $40 \%$. In other words, sample size would not change much whether the baseline success rate is $30 \%, 40 \%$, or $50 \%$.

In this section, the design with two built in interim analyses is discussed. Tables with required sample size for no or one interim analysis are provided in the appendix. All values are calculated with one-sided tests and using an un-pooled variance estimate. EAST software was used for sample size calculation [31].

Table 2 shows the required sample size for design with two interim analyses. Ideally, improvement of $20 \%$ of response rate (justification can be found in the discussion) with $90 \%$ power is recommended. For 1:1 randomization, each arm requires 108 patients. In 1:2 randomization, the standard care arm requires 81 patients while the treatment arm requires 162 patients. Comparing this table with Tables 5 and 6 in the appendix, sample size did not increase much from those with no or one interim analysis. Therefore, two interim analyses are recommended since it does not require many additional patients. We suggest inflating the sample size from the table by approximately $5 \%$ to account for the loss of information (such as dropout after randomization).

\section{Toxicity monitoring}

Since 1:2 randomization is recommended, we used the sample size value from Table 2 to compute toxicity boundaries ( $n=81$ and $n=162)$ at $25 \%$ toxicity level. A summarized toxicity boundary is presented in Table 3 . In Table 3, if the overall number of subjects is 5 and out of 5 if there are 2 cases of toxicities, then the trial should stop because the toxicity boundary of $25 \%$ is exceeded. $R$ computer program was used for toxicity boundary calculation [35]. The full toxicity boundaries can be found in Table 7 in appendix. 


\section{Result for high-risk group Sample size calculation}

For patients in the high-risk group, sample size is calculated based on different levels of improvement rate at $90 \%$ and $80 \%$ power with two interim analyses (Table 4). P0 is the 30 days mortality rate in the standard arm and P1 is the 30 days mortality rate in the treatment arm. The sample size is the estimated number of subjects that are required to bring down the mortality rate from P0 to P1. Typically, we recommend a reduction in mortality from $70 \%$ to $55 \%$ with $90 \%$ power. In this case, 133 patients should be enrolled for the standard arm, and 266 should be enrolled for the treatment arm. When conducting two interim analyses, to start with, one should enroll 45 patients for the standard arm and 89 patients for the treatment arm, then perform the first look. Similar procedure should be used for the second and third look. For results with one interim analysis and 1:1 randomization, see Table 8 in the appendix. For results with one interim analysis and 1:2 randomization, see Table 9 in the appendix. For results with two interim analyses and 1:1 randomization, see Table 10 in the appendix. Note that all options have nearly identical required sample size, and therefore, performing two interim analyses would be more cost-effective from risk-benefit perspective such as the increased cost of recruiting additional patients. We suggest inflating the sample size by approximately $5 \%$ to account for the loss of information (such as dropout after randomization). As noted in the respective tables, which can be used for other effect sizes, much larger sample size is required if the effect size is smaller.

\section{Discussion}

Designing a trial for testing the efficacy of therapeutic interventions for COVID-19 is challenging. The pandemic is new and there is little specific information about the virus and its adverse health effects. We do not yet clearly know the typical course of the infection, the range of susceptibility factors and the effects of co-morbid conditions. How the use of different medications, supplements and pharmaceuticals affect the severity of the infection also remain unknown. Whatever little information we currently have, is constantly being revised as new data become available. Nonetheless, it is important to develop streamlined clinical trial, designed with harmonized measures, questionnaires, biomarkers and clinical endpoints, so that the results of different trials could be compared. This is critically important in current circumstance, where a large number of clinical trials need to conducted, as rapidly as possible and with extraordinary
Table 2 Required Sample Size for Intermediate-Risk Group Patients with Two Interim Analyses

\begin{tabular}{|c|c|c|c|c|c|}
\hline \multirow[t]{2}{*}{$\begin{array}{l}\text { Effect } \\
\text { size }\end{array}$} & \multirow[b]{2}{*}{ Power } & \multicolumn{2}{|c|}{$\begin{array}{l}a=0.05 \text { with } 1: 1 \text { Group } \\
\text { Ratio }\end{array}$} & \multicolumn{2}{|c|}{$\begin{array}{l}a=0.05 \text { with } 1: 2 \text { Group } \\
\text { Ratio }\end{array}$} \\
\hline & & $80 \%$ & $90 \%$ & $80 \%$ & $90 \%$ \\
\hline \multirow[t]{3}{*}{$10 \%$} & N1 & 315 & 438 & 235 & 326 \\
\hline & N2 & 315 & 438 & 470 & 652 \\
\hline & Total & 630 & 876 & 705 & 978 \\
\hline \multirow[t]{3}{*}{$15 \%$} & $\mathrm{~N} 1$ & 140 & 194 & 104 & 145 \\
\hline & N2 & 140 & 194 & 208 & 290 \\
\hline & Total & 280 & 388 & 312 & 435 \\
\hline \multirow[t]{3}{*}{$20 \%$} & N1 & 78 & 108 & 58 & 81 \\
\hline & N2 & 78 & 108 & 116 & 162 \\
\hline & Total & 156 & 216 & 174 & 243 \\
\hline \multirow[t]{3}{*}{$25 \%$} & $\mathrm{~N} 1$ & 49 & 67 & 37 & 51 \\
\hline & N2 & 49 & 67 & 74 & 102 \\
\hline & Total & 98 & 134 & 111 & 153 \\
\hline \multirow[t]{3}{*}{$30 \%$} & N1 & 33 & 45 & 25 & 35 \\
\hline & N2 & 33 & 45 & 50 & 70 \\
\hline & Total & 66 & 90 & 75 & 105 \\
\hline \multirow[t]{3}{*}{$35 \%$} & $\mathrm{~N} 1$ & 23 & 32 & 18 & 25 \\
\hline & $\mathrm{N} 2$ & 23 & 32 & 36 & 50 \\
\hline & Total & 46 & 64 & 54 & 75 \\
\hline \multirow[t]{3}{*}{$40 \%$} & N1 & 17 & 23 & 13 & 18 \\
\hline & N2 & 17 & 23 & 26 & 36 \\
\hline & Total & 34 & 46 & 39 & 54 \\
\hline
\end{tabular}

N1: sample size for the standard care arm. N2: sample size for the treatment arm

Response rate $=40 \%$

For $80 \%$ power: probability of rejection at each look: $1^{\text {st }}$ look $p<0.002$, futility look $p>0.835,2^{\text {nd }}$ look $p<0.014$, futility look $p>0.312$, final look $p<0.046$ For $90 \%$ power: probability of rejection at each look: $1^{\text {st }}$ look $p<0.002$, futility look $p>0.830,2^{\text {nd }}$ look $p<0.014$, futility look $p>0.298$, final look $p<0.046$ $\rho=3.0$

Bold indicates recommended sample size with suggested parameters

care to ensure that maximal information could be extracted from each trial and the results obtained could be compared meaningfully with other trials in the field to administer effective therapies as soon as possible.

Many factors need careful consideration in designing clinical trials, and critical decisions have to be made regarding which parameters to include and which tests should be conducted. In developing model clinical trial designs here, we gathered information from recently published manuscripts [4-8, 10], while fully recognizing that these may need revision. However, based on currently available evidence, we have developed robust design that may require only minimal modification and updating for rapid implementation. 
Table 3 Abbreviated Toxicity Boundaries at Probability of Toxicity $=0.25$ and $a=0.01$

\begin{tabular}{|c|c|}
\hline Maximum Number of Subjects & Number of Subjects with Toxicities \\
\hline 5 & 2 \\
\hline 6 & 3 \\
\hline 8 & 4 \\
\hline 10 & 5 \\
\hline 12 & 6 \\
\hline 14 & 7 \\
\hline 16 & 8 \\
\hline 18 & 9 \\
\hline 20 & 10 \\
\hline 23 & 11 \\
\hline 25 & 12 \\
\hline 28 & 13 \\
\hline$\cdots$ & $\cdots$ \\
\hline 52 & 22 \\
\hline 55 & 23 \\
\hline$\cdots$ & $\cdots$ \\
\hline 79 & 31 \\
\hline 82 & 32 \\
\hline$\cdots$ & $\cdots$ \\
\hline 107 & 40 \\
\hline 110 & 41 \\
\hline$\cdots$ & $\cdots$ \\
\hline 158 & 56 \\
\hline 161 & 57 \\
\hline 164 & 58 \\
\hline
\end{tabular}

To aid rapid and robust clinical evaluation, our trials have been designed for feasibility and for minimizing the number of participants required. Even though ideally, for a balanced design many known factors should be considered for stratification, we have selected only the most basic demographic parameters, as too many strata require much larger sample size. On the basis of currently available evidence, the stratification factors considered in our design seem most appropriate and generally-applicable to us; however, investigators should pick the factors that are most suitable for their patients and for the specific requirements of the trial. The stratification factors that we include in our design - age, sex and cardiovascular disease risk seem fundamental to the etiology of the infection, which seems primarily to affect older male individuals with pre-existing cardiovascular disease or cardiovascular disease risk [36].
Table 4 Required Sample Size for High-Risk Group Patients with Two Interim Analyses

Required Sample Size for High-Risk Group Patients with Two Interim Analyses

\begin{tabular}{|c|c|c|c|c|c|c|c|c|c|c|c|c|}
\hline \multirow[b]{3}{*}{ P1 } & \multicolumn{6}{|c|}{ Power $=80 \%$} & \multicolumn{6}{|c|}{ Power $=90 \%$} \\
\hline & \multicolumn{3}{|c|}{$\mathrm{PO}=80 \%$} & \multicolumn{3}{|c|}{$\mathrm{PO}=70 \%$} & \multicolumn{3}{|c|}{$P 0=80 \%$} & \multicolumn{3}{|c|}{$P 0=70 \%$} \\
\hline & N1 & N2 & Total & N1 & $\mathrm{N} 2$ & Total & N1 & $\mathrm{N} 2$ & Total & $\mathrm{N} 1$ & $\mathrm{~N} 2$ & Total \\
\hline $70 \%$ & 171 & 342 & 513 & NA & NA & NA & 237 & 474 & 711 & NA & NA & NA \\
\hline $65 \%$ & 79 & 158 & 237 & 833 & 1666 & 2499 & 109 & 218 & 327 & 1155 & 2310 & 3465 \\
\hline $60 \%$ & 45 & 90 & 135 & 213 & 426 & 639 & 63 & 126 & 189 & 295 & 590 & 885 \\
\hline $55 \%$ & 30 & 60 & 90 & 96 & 192 & 288 & 41 & 82 & 123 & 133 & 266 & 399 \\
\hline $50 \%$ & 21 & 42 & 63 & 54 & 108 & 162 & 29 & 58 & 87 & 75 & 150 & 225 \\
\hline $45 \%$ & 15 & 30 & 45 & 35 & 70 & 103 & 21 & 42 & 63 & 48 & 96 & 144 \\
\hline $40 \%$ & 12 & 24 & 34 & 24 & 48 & 72 & 16 & 32 & 48 & 33 & 66 & 99 \\
\hline $35 \%$ & NA & NA & NA & 17 & 34 & 51 & NA & NA & NA & 24 & 48 & 72 \\
\hline
\end{tabular}

P0: 30 days mortality rate in the standard arm. $\mathrm{P} 1: 30$ days mortality rate in the treatment arm

N1: sample size for the standard care arm. N2: sample size for the treatment arm

For $80 \%$ power: probability of rejection at each look: $1^{\text {st }}$ look $p<0.002$, futility look $p>0.835,2^{\text {nd }}$ look $p<0.014$, futility look $p>0.312$, final look $p<0.046$ For $90 \%$ power: probability of rejection at each look: $1^{\text {st }}$ look $p<0.002$, futility look $p>0.830,2^{\text {nd }}$ look $p<0.014$, futility look $p>0.298$, final look $p<0.046$

$1: 2$ randomization; $\rho=3.0$

Bold indicates recommended sample size with suggested parameters

Reasons for the high susceptibility of individuals with cardiovascular disease risk for COVID-19 remain unclear and are under intense investigation, but it has been speculated that conditions associated with chronic unresolved inflammation - such as diabetes, obesity, cardiovascular disease, which are characterized by intrinsic immune dysfunction leading to inflammation may enhance the risk of severe infection and more severe outcomes [37]. Although there are significant racial and ethnic difference in susceptibility to cardiovascular disease $[38,39]$, there is little evidence to support racial differences per se and not race-specific differences in cardiovascular disease burden affect COVID-19 severity. However, should emerging data indicate that race is an important determinant of the severity of infection or its outcomes, independent of pre-existing cardiovascular disease risk, it could be used for additional stratification of the patient population. Additionally, if a trial is designed to assess pulmonary or renal outcomes, stratification based on lung or kidney function may be important. Note that it is important to consider stratification factors and balance the randomization so that tests for comparing the two groups would be unbiased.

As an alternative to stratified block randomization, one can use dynamic randomization [40]. In dynamic randomization, more stratification factors can be accommodated. For example, considering site as a stratification factor, assuming many sites are conducting study, the dynamic randomization can be useful. As a hypothetical example with 20 sites, sex, 
COVID-19 severity (at two level) and a co-morbidity (at two level) as stratification, a dynamic randomization can be used to minimize balance 1:1 allocation within each of 160 strata $(20 \times 2 \times 2 \times 2)$. However, a constant involvement of statistics team and implementation of the allocation approach make the process cumbersome. Also, when the treatment allocation is not equal (1:1), but different (such as 2:1), the probability calculation for allowable difference in allocation becomes much harder. To simplify, when there is frequent communication among sites, it is realistic to drop site as a stratification factor and use a stratified block randomization to implement $1: 1$ or 2:1 allocation. It is also easier to use a stratified $\mathrm{z}$ score to draw the inference.

Table 11 in appendix provides critical values for decision making. The test statistic, $\mathrm{Z}$, is based on the ratio of difference in estimated response rates and corresponding pooled standard error estimate. Because we are proposing a stratified randomized design, the test statistics needs to be estimated within each stratum and then pooled together. It may be noted that testing the equality of two response probabilities can be easily formulated in terms of testing the odds ratio. Then, one can obtain the stratified $\mathrm{Z}$ statistic, as described in Srivastava et al., and compare it to the cut-off provided in Table 11 in appendix to decide if the trial should be stopped at an interim analysis [26]. Adjusting for additional covariates or constructing confidence intervals for estimate of effect at interim analyses are not straightforward and requires additional considerations [30].

In the design of our clinical trials, we focused on primary outcomes. In general, mortality as the primary outcome seems appropriate at least for advanced stage patients, while for intermediate risk patients, looking at the proportion of patients discharged from hospital by the $15^{\text {th }}$ day appears more appropriate. However, different primary endpoints may be considered, which along with appropriately selected secondary endpoints could provide important mechanistic information. Current evidence suggests that even though COVID-19 significantly impairs tissue function, much of the tissue injury is mediated by the resultant IL-6-driven cytokine storm that exacerbates pulmonary injury and may further damage other peripheral organs as has been reported for SARS [41-43]. Therefore, an intervention designed to decrease viral load, may be only marginally efficacious in preventing clinical symptoms, even though it might lead to a significant decrease in viral load, after the cytokine storm has already been initiated. Similarly, interventions targeted at proinflammatory cytokines (e.g., with antibodies) may not affect the viral load but significantly attenuate the subsequent response and clinical outcomes. Hence, to understand such non-linear relationships between infection and response, it may be important to judiciously select a panel of biomarkers informative of the immune response and its resolution at different stages of clinical disease progression.

In addition to monitoring biochemical, physiological and clinical responses, investigators should also be attentive to toxicity due to the therapeutic intervention per se. However, deciding upon an optimal toxicity monitoring rate is problematic, especially in a patient population with a high death rate, as is the case with advanced stage COVID-19 patients. A systematic toxicity monitoring rule is discussed, and its usage is suggested [44-47]. Usually Dose Limiting Toxicity (DLT) probability is assumed at $33 \%$ in Phase I cancer clinical trials, although a limit lower than 33\% can be advocated. Yao et al. used a $21 \%$ toxicity rate in the previous trial and Ivanova et al. used a toxicity rate of $20 \%$ and $25 \%$ $[48,49]$. Based on our 2-decades of experience in designing clinical trials, we suggest using a toxicity rate of $25 \%$. The assumption here is that toxicities are manageable with some treatment if the patient is cured from COVID-19. Also, many of the drugs that are being evaluated in this population (such as Remdesvir) are already approved for another indication by FDA. Codes for calculating toxicity boundaries have been published before [50].

We have designed our clinical trials with the expectation that the treatment or intervention is likely to be more effective than standard care, hence all standard tests in the work were conducted onesided. This could be readily ascertained during the interim analysis. Nevertheless, in some scenarios where the intervention is clearly not working or causing unacceptable toxicity, it may be appropriate to discontinue the trial and to test a different intervention. But usually this is difficult to establish, and therefore, care should be taken to continue the trial to its entirety, while monitoring closely to higher toxicity rates, particularly in intermediate stage patients.

For the intermediate-risk group, we suggest using a response rate of $20 \%$. If it is desirable to have a lower response rate, for example, $10 \%$, then the trial requires a much larger sample size (around 900 as shown in Table 2), and it is more likely to be a multicenter trial. However, it is usually not cost-effective to have such a large sample size to detect only $10 \%$ response rate. Nevertheless, we have provided sample size for different response rate in case someone is interested in conducting trials with response rates other 
than $20 \%$. Note that when conducting a multicenter trial, no stratification should be conducted on centers.

We suggest inflating sample size very marginally (approximately $5 \%$ ) from our calculation as normally an inflation of $10 \%$ to $20 \%$ is performed in regular clinical studies. The reason is that COVID-19 patients are unlikely to be lost in the follow up since could be a lethal disease, and enrolled patients in both the intermediaterisk group and high-risk group are likely to be quarantined in the hospital for an extended period of time. Therefore, we suggest inflation of the sample size by only $5 \%$ to account for unexpected events, such as suicide or patient dropout after randomization.

\section{Conclusions}

For the intermediate-risk patient group, we suggest using a composite endpoints design with two interim analyses and four factors stratification. The use of 1:2 randomization is recommended for broader patient benefit. Toxicity monitoring is acceptable at $25 \%$ level. For clinical trials with this patient population, we suggest that it is optimal to use $90 \%$ power and an improvement of $20 \%$ response rate (such as from $40 \%$ in the standard arm to $60 \%$ in the treatment arm).

For the high-risk patient group, we recommend a clinical trials design targeting the improvement of 30-day mortality with two interim analyses and three factors stratification. Given the precarious condition of patients in this group, no toxicity monitoring is needed. We suggest that for this group, the use of 1:2 randomization is ideal, and that a $15 \%$ reduction in the 30 day mortality rate (from $70 \%$ in the standard arm to $55 \%$ in the treatment arm) may be an optimal measure of acceptable efficacy.

\section{Appendix}

Partial list of drugs/therapies currently under investigation for COVID-19 treatment

Andrographolide (In Silico, Molecular Docking).

Antisense RNA (In Vitro).

Bacillus Calmette-Guérin (BCG) (A total 19 Vaccine Clinical Studiess are underway, two in Netherlands, one in Colombia, one in South Africa, two in Egypt, one in India, one in Mexico, one in Australia, one in Brazil, one in Greece, one in Denmark, one in Tunisia, one in France, one in US, one in Canada, 2in Germany and one in Guinea Bissau).

Benzyl-quinazolin-4-yl-amine (Potential Repurpose drug using Bioinformatics).

Bevacizumab (Pilot Clinical trial underway in China).

Camptothecin (Potential Repurpose drug using Bioinformatics).
Carfilzomib (Possible candidate for inhibitory activities against SARS-CoV-2 main protease).

Chloroquine (phosphate) (Clinical trial results published based on a study in China. Eighty-two studies are listed in clinicaltrials.gov as of 07/18/2020).

Convalescent plasma therapy (Clinical study results published. One hundred seven studies are listed in clinicaltrials.gov as of $07 / 18 / 2020$ ).

Degarelix (Clinical trial underway in the US).

Didanosine (Potential Repurpose drug using Bioinformatics).

Duvelisib (Phase IItrial underway in the US).

Elbasvir (In Silico, Possible candidate for inhibitory activities against SARS-CoV-2 main protease).

Eravacycline (Possible candidate for inhibitory activities against SARS-CoV-2 main protease).

Favilavir (Approved as an experimental drug in China).

Favipiravir (Clinical trial results published, currently marketed in India and China).

Febuxosstat (FBX) (Clinical trial manuscript accepted).

Human immunoglobulin/Convalescent plasma Therapy (Clinical trial results published, and many are underway)).

Hydroxychloroquine plus Azithromycin (Clinical trial results published; forty-three studies are listed in clinicaltrials.gov as of 07/18/2020).

Interferon lambda (Potential Therapeutic Intervention).

Interferons, Arbidol (Eight studies are listed in clinicaltrials.gov as of 07/18/2020).

Lopinavir/Ritonavir (Clinical trial results published; eighty studies are listed in clinicaltrials.gov as of $07 / 18$ / 2020).

Macrolides (MAC) (Potential drug candidate).

Methylprednisolone (Clinical study results published. WHO and CDC generally not recommend due to mortality risk and other complications.)

Nitazoxanide (Potential drug candidate with Azithromycin, sixteen studies are listed in clinicaltrials.gov as of 07/18/2020).

R0-90-7501 (Potential Repurpose drug using Bioinformatics).

Remdesivir (GS-5734) (GS-441524) (Clinical trial and compassionate study results published. FDA has approved Remdesvir for COVID-19.)

Sarilumab (Potential drug candidate. Seventeen studies are listed in clinicaltrials.gov as of 07/18/2020).

Tocilizumab (Clinical study results published, fifty-nine studies are listed in clinicaltrials.gov as of 07/18/2020).

Valrubicin (Potential drug candidate).

Vitamin C (Clinical trial underway in Wuhan, China).

Vitamin D (Thirty-one studies are listed in clinicaltrials.gov as of $07 / 18 / 2020$ ).

Zinc (Eighteen studies are listed in clinicaltrials.gov as of $07 / 18 / 2020)$. 
Table 5 Required Sample Size for Intermediate-Risk Group Patients with No Interim Analysis

\begin{tabular}{|c|c|c|c|c|c|}
\hline \multirow[t]{2}{*}{$\begin{array}{l}\text { Effect } \\
\text { Size }\end{array}$} & \multirow[b]{2}{*}{ Power } & \multicolumn{2}{|c|}{$\begin{array}{l}a=0.05 \text { with } 1: 1 \text { Group } \\
\text { Ratio }\end{array}$} & \multicolumn{2}{|c|}{$\begin{array}{l}a=0.05 \text { with } 1: 2 \text { Group } \\
\text { Ratio }\end{array}$} \\
\hline & & $80 \%$ & $90 \%$ & $80 \%$ & $90 \%$ \\
\hline \multirow[t]{3}{*}{$10 \%$} & $\mathrm{~N} 1$ & 303 & 420 & 226 & 313 \\
\hline & N2 & 303 & 420 & 452 & 626 \\
\hline & Total & 606 & 840 & 678 & 939 \\
\hline \multirow[t]{3}{*}{$15 \%$} & $\mathrm{~N} 1$ & 134 & 186 & 100 & 139 \\
\hline & N2 & 134 & 186 & 200 & 278 \\
\hline & Total & 268 & 372 & 300 & 417 \\
\hline \multirow[t]{3}{*}{$20 \%$} & $\mathrm{~N} 1$ & 75 & 103 & 56 & 78 \\
\hline & N2 & 75 & 103 & 112 & 156 \\
\hline & Total & 150 & 206 & 168 & 234 \\
\hline \multirow[t]{3}{*}{$25 \%$} & $\mathrm{~N} 1$ & 47 & 65 & 35 & 49 \\
\hline & N2 & 47 & 65 & 70 & 98 \\
\hline & Total & 94 & 130 & 105 & 147 \\
\hline \multirow[t]{3}{*}{$30 \%$} & $\mathrm{~N} 1$ & 31 & 43 & 24 & 33 \\
\hline & N2 & 31 & 43 & 48 & 66 \\
\hline & Total & 62 & 86 & 72 & 99 \\
\hline \multirow[t]{3}{*}{$35 \%$} & $\mathrm{~N} 1$ & 22 & 30 & 17 & 24 \\
\hline & N2 & 22 & 30 & 34 & 48 \\
\hline & Total & 44 & 60 & 51 & 72 \\
\hline \multirow[t]{3}{*}{$40 \%$} & $\mathrm{~N} 1$ & 16 & 22 & 13 & 18 \\
\hline & N2 & 16 & 22 & 26 & 36 \\
\hline & Total & 32 & 44 & 39 & 54 \\
\hline
\end{tabular}

N1: sample size for the standard care arm. N2: sample size for the treatment arm

Response rate $=40 \%$
Table 6 Required Sample Size for Intermediate-Risk Group Patients with One Interim Analysis

Required Sample Size for Intermediate-Risk Group Patients with One Interim Analysis

\begin{tabular}{|c|c|c|c|c|c|}
\hline \multirow[t]{2}{*}{$\begin{array}{l}\text { Effect } \\
\text { Size }\end{array}$} & \multirow[b]{2}{*}{ Power } & \multicolumn{2}{|c|}{$\begin{array}{l}a=0.05 \text { with } 1: 1 \text { Group } \\
\text { Ratio }\end{array}$} & \multicolumn{2}{|c|}{$\begin{array}{l}a=0.05 \text { with } 1: 2 \text { Group } \\
\text { Ratio }\end{array}$} \\
\hline & & $80 \%$ & $90 \%$ & $80 \%$ & $90 \%$ \\
\hline \multirow[t]{3}{*}{$10 \%$} & N1 & 313 & 433 & 234 & 323 \\
\hline & N2 & 313 & 433 & 468 & 646 \\
\hline & Total & 626 & 866 & 702 & 969 \\
\hline \multirow[t]{3}{*}{$15 \%$} & N1 & 139 & 192 & 104 & 143 \\
\hline & N2 & 139 & 192 & 208 & 286 \\
\hline & Total & 278 & 384 & 312 & 429 \\
\hline \multirow[t]{3}{*}{$20 \%$} & N1 & 77 & 106 & 58 & 80 \\
\hline & N2 & 77 & 106 & 116 & 160 \\
\hline & Total & 154 & 212 & 174 & 240 \\
\hline \multirow[t]{3}{*}{$25 \%$} & N1 & 48 & 67 & 37 & 50 \\
\hline & N2 & 48 & 67 & 74 & 100 \\
\hline & Total & 96 & 134 & 111 & 150 \\
\hline \multirow[t]{3}{*}{$30 \%$} & N1 & 32 & 45 & 25 & 34 \\
\hline & N2 & 32 & 45 & 50 & 68 \\
\hline & Total & 64 & 90 & 75 & 102 \\
\hline \multirow[t]{3}{*}{$35 \%$} & N1 & 23 & 31 & 18 & 25 \\
\hline & N2 & 23 & 31 & 36 & 50 \\
\hline & Total & 46 & 62 & 54 & 75 \\
\hline \multirow[t]{3}{*}{$40 \%$} & N1 & 16 & 23 & 13 & 18 \\
\hline & N2 & 16 & 23 & 26 & 36 \\
\hline & Total & 32 & 46 & 39 & 54 \\
\hline
\end{tabular}

N1: sample size for the standard care arm. N2: sample size for the treatment arm

Response rate $=40 \%$

For $80 \%$ power: probability of rejection at each look: $1^{\text {st }}$ look $p<0.006$, futility look $p>0.709$, final look $p<0.047$

For $90 \%$ power: probability of rejection at each look: $1^{\text {st }}$ look $p<0.006$, futility look $p>0.716$, final look $p<0.047$ $p=2.0$ 
Table 7 Full Toxicity Boundaries Table at Probability of Toxicity $=0.25$ and $a=0.01$

\begin{tabular}{|c|c|c|c|}
\hline \multicolumn{2}{|c|}{ Full Toxicity Boundaries Table at Probability of Toxicity $=0.25$ and $a=0.01$} & \multicolumn{2}{|c|}{ Full Toxicity Boundaries Table at Probability of Toxicity $=0.25$ and $a=0.01$} \\
\hline $\begin{array}{l}\text { Maximum Number of } \\
\text { Subjects }\end{array}$ & $\begin{array}{l}\text { Number of Subjects with } \\
\text { Toxicities }\end{array}$ & $\begin{array}{l}\text { Maximum Number of } \\
\text { Subjects }\end{array}$ & $\begin{array}{l}\text { Number of Subjects with } \\
\text { Toxicities }\end{array}$ \\
\hline 5 & 2 & 119 & 44 \\
\hline 6 & 3 & 122 & 45 \\
\hline 8 & 4 & 126 & 46 \\
\hline 10 & 5 & 129 & 47 \\
\hline 12 & 6 & 132 & 48 \\
\hline 14 & 7 & 135 & 49 \\
\hline 16 & 8 & 138 & 50 \\
\hline 18 & 9 & 142 & 51 \\
\hline 20 & 10 & 145 & 52 \\
\hline 23 & 11 & 148 & 53 \\
\hline 25 & 12 & 151 & 54 \\
\hline 28 & 13 & 155 & 55 \\
\hline 30 & 14 & 158 & 56 \\
\hline 33 & 15 & 161 & 57 \\
\hline 36 & 16 & 164 & 58 \\
\hline
\end{tabular}

Table 7 Full Toxicity Boundaries Table at Probability of Toxicity $=0.25$ and $a=0.01$ (Continued)

Table 8 Required Sample Size for High-Risk Group Patients with One Interim Analysis

Required Sample Size for High-Risk Group Patients with One Interim Analysis

\begin{tabular}{llllll}
\hline & \multicolumn{2}{l}{ Power $=80 \%$} & & & Power $=90 \%$ \\
\cline { 2 - 3 } \cline { 5 - 6 } P1 & P0 $=80 \%$ & P0 $=70 \%$ & & P0 $=80 \%$ & P0 $=70 \%$ \\
\hline $70 \%$ & 473 & NA & & 654 & NA \\
$65 \%$ & 220 & 2235 & & 305 & 3092 \\
$60 \%$ & 128 & 575 & & 177 & 795 \\
$55 \%$ & 84 & 260 & & 116 & 360 \\
$50 \%$ & 59 & 147 & & 81 & 204 \\
$45 \%$ & 43 & 94 & & 59 & 130 \\
$40 \%$ & 32 & 64 & & 45 & 89 \\
$35 \%$ & NA & 46 & & NA & 64 \\
\hline
\end{tabular}

P0: 30 days mortality rate in the standard arm. P1: 30 days mortality rate in the treatment arm

N1: sample size for the standard care arm. N2: sample size for the treatment arm

For $80 \%$ power: probability of rejection at each look: $1^{\text {st }}$ look $p<0.006$, futility look $p>0.709$, final look $p<0.047$

For $90 \%$ power: probability of rejection at each look: $1^{\text {st }}$ look $p<0.006$, futility look $p>0.716$, final look $p<0.047$

1:1 randomization; $\rho=2.0$. NA $=$ Not Applicable 
Table 9 Required Sample Size for High-Risk Group Patients with One Interim Analysis

\begin{tabular}{|c|c|c|c|c|c|c|c|c|c|c|c|c|}
\hline \multirow[b]{3}{*}{$\mathrm{P} 1$} & \multicolumn{6}{|c|}{ Power $=80 \%$} & \multicolumn{6}{|c|}{ Power $=90 \%$} \\
\hline & \multicolumn{3}{|c|}{$\mathrm{PO}=80 \%$} & \multicolumn{3}{|c|}{$\mathrm{PO}=70 \%$} & \multicolumn{3}{|c|}{$\mathrm{PO}=80 \%$} & \multicolumn{3}{|c|}{$P 0=70 \%$} \\
\hline & N1 & N2 & Total & N1 & N2 & Total & N1 & $\mathrm{N} 2$ & Total & N1 & N2 & Total \\
\hline $70 \%$ & 170 & 340 & 510 & NA & NA & NA & 235 & 470 & 705 & NA & NA & NA \\
\hline $65 \%$ & 78 & 156 & 234 & 827 & 1654 & 2481 & 108 & 216 & 324 & 1144 & 2288 & 3432 \\
\hline $60 \%$ & 45 & 90 & 135 & 211 & 422 & 633 & 62 & 124 & 186 & 292 & 584 & 876 \\
\hline $55 \%$ & 29 & 58 & 87 & 95 & 190 & 285 & 41 & 82 & 123 & 132 & 264 & 396 \\
\hline $50 \%$ & 21 & 42 & 63 & 54 & 108 & 162 & 28 & 56 & 84 & 74 & 148 & 222 \\
\hline $45 \%$ & 15 & 30 & 45 & 35 & 70 & 105 & 21 & 42 & 63 & 48 & 96 & 144 \\
\hline $40 \%$ & 12 & 24 & 36 & 24 & 48 & 72 & 16 & 32 & 48 & 33 & 66 & 99 \\
\hline $35 \%$ & NA & NA & NA & 17 & 34 & 51 & NA & NA & NA & 24 & 48 & 72 \\
\hline
\end{tabular}

P0: 30 days mortality rate in the standard arm. P1: 30 days mortality rate in the treatment arm

N1: sample size for the standard care arm. N2: sample size for the treatment arm

For $80 \%$ power: probability of rejection at each look: $1^{\text {st }}$ look $p<0.006$, futility look $p>0.709$, final look $p<0.047$

For $90 \%$ power: probability of rejection at each look: $1^{\text {st }}$ look $p<0.006$, futility look $p>0.716$, final look $p<0.047$

$1: 2$ randomization; $p=2$

Table 10 Required Sample Size for High-Risk Group Patients with Two Interim Analyses

Required Sample Size for High-Risk Group Patients with Two Interim Analyses

\begin{tabular}{|c|c|c|c|c|}
\hline \multirow[b]{2}{*}{ P1 } & \multicolumn{2}{|c|}{ Power $=80 \%$} & \multicolumn{2}{|c|}{ Power $=90 \%$} \\
\hline & $P 0=80 \%$ & $P 0=70 \%$ & $P 0=80 \%$ & $P 0=70 \%$ \\
\hline $70 \%$ & 476 & NA & 660 & NA \\
\hline $65 \%$ & 222 & 2250 & 308 & 3122 \\
\hline $60 \%$ & 129 & 579 & 179 & 803 \\
\hline $55 \%$ & 84 & 262 & 117 & 363 \\
\hline $50 \%$ & 59 & 148 & 82 & 206 \\
\hline $45 \%$ & 43 & 95 & 60 & 131 \\
\hline $40 \%$ & 33 & 65 & 45 & 90 \\
\hline $35 \%$ & NA & 46 & NA & 64 \\
\hline
\end{tabular}

P0: 30 days mortality rate in standard arm. P1: 30 days mortality rate in treatment arm

For $80 \%$ power: probability of rejection at each look: $1^{\text {st }}$ look $p<0.002$, futility look $p>0.835,2^{\text {nd }}$ look $p<0.015$, futility look $p>0.312$, final look $p<0.046$ For $90 \%$ power: probability of rejection at each look: $1^{\text {st }}$ look $p<0.002$, futility look $p>0.830,2^{\text {nd }}$ look $p<0.015$, futility look $p>0.297$, final look $p<0.046$

1:1 randomization; $\rho=3.0$. NA $=$ Not Applicable 
Table 11 Stopping Boundaries for Z Statistics and P-values

\begin{tabular}{|c|c|c|c|c|c|c|c|c|c|c|}
\hline \multicolumn{11}{|c|}{ Stopping Boundaries for Z Statistics and P-values } \\
\hline & $\begin{array}{l}Z \text { at } 1^{\text {st }} \\
\text { Interim }\end{array}$ & $\begin{array}{l}\mathrm{P} \text { at } 1^{\text {st }} \\
\text { Interim }\end{array}$ & $\begin{array}{l}Z \text { at } 1^{\text {st }} \\
\text { Futility }\end{array}$ & $\begin{array}{l}\text { P at } 1^{\text {st }} \\
\text { Futility }\end{array}$ & $\begin{array}{l}Z \text { at } 2^{\text {nd }} \\
\text { Interim }\end{array}$ & $\begin{array}{l}\mathrm{P} \text { at } 2^{\text {nd }} \\
\text { Interim }\end{array}$ & $\begin{array}{l}Z \text { at } 2^{\text {nd }} \\
\text { Futility }\end{array}$ & $\begin{array}{l}P \text { at } 2^{\text {nd }} \\
\text { Futility }\end{array}$ & $\begin{array}{l}\text { Final } \\
Z\end{array}$ & $\begin{array}{l}\text { Final } \\
P\end{array}$ \\
\hline \multicolumn{11}{|l|}{ Intermediate Risk Group } \\
\hline $\begin{array}{l}\text { For Design with } 1 \text { Interim } \\
\text { Analysis }\end{array}$ & 2.539 & 0.006 & -0.571 & 0.716 & NA & NA & NA & NA & 1.673 & 0.047 \\
\hline $\begin{array}{l}\text { For Design with } 2 \text { Interim } \\
\text { Analyses }\end{array}$ & 2.902 & 0.002 & -0.954 & 0.830 & 2.199 & 0.014 & 0.530 & 0.298 & 1.689 & 0.046 \\
\hline \multicolumn{11}{|l|}{ High Risk Group } \\
\hline $\begin{array}{l}\text { For Design with } 1 \text { Interim } \\
\text { Analysis }\end{array}$ & -2.539 & 0.006 & 0.571 & 0.716 & NA & NA & NA & NA & -1.673 & 0.047 \\
\hline $\begin{array}{l}\text { For Design with } 2 \text { Interim } \\
\text { Analyses }\end{array}$ & -2.902 & 0.002 & 0.954 & 0.830 & -2.199 & 0.014 & -0.530 & 0.298 & -1.689 & 0.046 \\
\hline
\end{tabular}

All values were calculated based on $90 \%$ power

\section{Abbreviations}

COVID-19: Coronavirus Disease; CVD: Cardiovascular Disease; COMET: Core Outcome Measures in Effectiveness Trials; COS: Core Outcome Set; RTPCR: Reverse Transcription Polymerase Chain Reaction; ECMO: Extracorporeal Membrane Oxygenation; HbA1C: Hemoglobin A1C; MI: Myocardial Infarction; ICU: Intensive Care Unit; IMV: Invasive Mechanical Ventilation; FDA: United States Food and Drug Administration; CTCAE: Common Terminology Criteria for Adverse Events; DSMB: Data and Safety Monitoring Board; DLT: Dose Limiting Toxicity

\section{Acknowledgements}

Not applicable.

\section{Authors' contributions}

Conception \& Design: SNR, CQ, JP, DKS. Data analysis: JP, DKS. Original Draft: $S N R, C Q, A S, A B$. Critical Input: AS, AB. Review \& Editing: All Authors. Manuscript Revision: All Authors. Approval of the Final Version: All Authors.

\section{Funding}

A. Bhatnagar was supported in part by a grant from the James Graham Brown Foundation and the Owsley Brown II Family Foundation. C. Qian was supported by the University of Louisville Fellowship. S. N. Rai was partly supported with Wendell Cherry Chair in Clinical Trial Research Fund, multiple National Institutes of Health (NIH) grants (5P20GM113226, PI: McClain; 1P42ES023716, PI: Srivastava; 5P30GM127607-02, PI: Jones; 1P20GM125504-01, PI: Lamont; 2U54HL120163, PI: Bhatnagar/Robertson; 1P20GM135004, PI: Yan; 1R35ES0238373-01, PI: Cave; 1R01ES029846, PI: Bhatnagar; 1R01ES027778-01A1, PI: States;), and Kentucky Council on Postsecondary Education grant (PON2 415 1900002934, Pl: Chesney).

\section{Availability of data and materials}

Not applicable.

\section{Ethics approval and consent to participate}

Not applicable.

\section{Consent for publication}

Not applicable.

\section{Competing interests}

The authors declare that they have no competing interests.

\section{Author details}

${ }^{1}$ Biostatistics and Bioinformatics Facility, James Graham Brown Cancer Center, University of Louisville, Louisville, KY 40202, USA. ²Department of Biostatistics and Bioinformatics, University of Louisville, Louisville, KY 40202, USA. ${ }^{3}$ SK Patent Associates, LLC, Dublin, OH 43016, USA. ${ }^{4}$ Department of Biostatistics, St. Jude Children's Research Hospital, Memphis, TN 38105, USA. ${ }^{5}$ Department of Medicine, Christina Lee Brown Envirome Institute, University of Louisville, Louisville, KY 40202, USA.
Received: 21 May 2020 Accepted: 13 August 2020

Published online: 31 August 2020

\section{References}

1. Beigel JH, Tomashek KM, Dodd LE, Mehta AK, Zingman BS, Kalil AC, et al. Remdesivir for the treatment of Covid-19 - preliminary report. N Engl J Med. 2020:NEJMoa2007764. https://doi.org/10.1056/NEJMoa2007764.

2. Wang Y, Zhang D, Du G, Du R, Zhao J, Jin Y, et al. Remdesivir in adults with severe COVID-19: a randomised, double-blind, placebo-controlled, multicentre trial. Lancet. 2020;395:1569-78. https://doi.org/10.1016/S01406736(20)31022-9.

3. Alexander PE, Debono VB, Mammen MJ, lorio A, Aryal K, Deng D, et al. COVID-19 coronavirus research has overall low methodological quality thus far: case in point for chloroquine/hydroxychloroquine. J Clin Epidemiol. 2020;123:120-6. https://doi.org/10.1016/j.jclinepi.2020.04.016.

4. Gautret $\mathrm{P}$, Lagier JC, Parola P, Hoang VT, Meddeb L, Mailhe M, et al. Hydroxychloroquine and azithromycin as a treatment of COVID-19: results of an open-label non-randomized clinical trial. Int J Antimicrob Agents. 2020:105949. https://doi.org/10.1016/j.jjantimicag.2020.105949.

5. Borba MGS, Val FFA, Sampaio VS, Alexandre MAA, Melo GC, Brito M, et al. Effect of high vs low doses of chloroquine diphosphate as adjunctive therapy for patients hospitalized with severe acute respiratory syndrome coronavirus 2 (SARS-CoV-2) infection: a randomized clinical trial. JAMA Netw Open. 2020;3(4): e208857. https://doi.org/10.1001/jamanetworkopen.2020.8857.

6. Hung IF, Lung KC, Tso EY, Liu R, Chung TW, Chu MY, et al. Triple combination of interferon beta-1b, lopinavir-ritonavir, and ribavirin in the treatment of patients admitted to hospital with COVID-19: an open-label, randomised, phase 2 trial. Lancet. 2020;395(10238):1695-704. https://doi.org/ 10.1016/S0140-6736(20)31042-4.

7. Davoodi L, Abedi SM, Salehifar E, Alizadeh-Navai R, Rouhanizadeh H, Khorasani G, et al. Febuxostat therapy in outpatients with suspected COVID-19: a clinical trial. Int J Clin Pract. 2020:e13600. https://doi.org/10. $1111 /$ ijcp. 13600

8. Cao B, Wang Y, Wen D, Liu W, Wang J, Fan G, et al. A trial of lopinavirritonavir in adults hospitalized with severe COVID-19. N Engl J Med. 2020; 382(19):1787-99. https://doi.org/10.1056/NEJMoa2001282.

9. Gautret P, Lagier JC, Parola P, Hoang VT, Meddeb L, Mailhe M, et al. Hydroxychloroquine and azithromycin as a treatment of COVID-19: results of an open-label non-randomized clinical trial. Int J Antimicrob Agents. 2020;56(1):105949. https://doi.org/10.1016/.ijantimicag.2020.105949.

10. Boulware DR, Pullen MF, Bangdiwala AS, Pastick KA, Lofgren SM, Okafor EC, et al. A randomized trial of hydroxychloroquine as Postexposure prophylaxis for Covid-19. N Engl J Med. 2020:NEJMoa2016638. https://doi.org/10.1056/ NEJMoa2016638.

11. Eichler HG, Cavaleri M, Enzmann H, Scotti F, Sepodes B, Sweeney F, et al. Clinical trials for COVID-19: can we better use the short window of opportunity? Clin Pharmacol Ther. 2020. https://doi.org/10.1002/cpt.1891.

12. R\&D Coronavirus disease (COVID-2019) R\&D. Geneva: World Health Organization. [cited 2020 July 23]; Available from: http://www.who.int/ blueprint/priority-diseases/key-action/novel-coronavirus/en/. 
13. Wang Y, Fan G, Horby P, Hayden F, Li Q, Wu Q, et al. Comparative outcomes of adults hospitalized with seasonal influenza a or B virus infection: application of the 7-category ordinal scale. Open Forum Infect Dis. 2019;6(3):ofz053. https://doi.org/10.1093/ofid/ofz053.

14. Merton K, Davies MJ, Vijapurkar U, Inman D, Meininger G. Achieving the composite endpoint of $\mathrm{HbA1c}$, body weight, and systolic blood pressure reduction with canagliflozin in patients with type 2 diabetes. Curr Med Res Opin. 2018;34(2):313-8

15. Stolker JM, Spertus JA, Cohen DJ, Jones PG, Jain KK, Bamberger E, et al. Rethinking composite end points in clinical trials: insights from patients and trialist. Circulation. 2014;130(15):1254-61.

16. DeMets DL, Califf RM. Response to: combining composite endpoints: counterintuitive or a mathematical impossibility? Circulation. 2003; 107(9):e70.

17. Lim E, Brown A, Helmy A, Mussa S, Altman DG. Composite outcomes in cardiovascular research: a survey of randomized trials. Ann Intern Med. 2008; 149(9):612-7.

18. Lewnard JA, Liu VX, Jackson ML, Schmidt MA, Jewell BL, Flores JP, et al. Incidence, clinical outcomes, and transmission dynamics of severe coronavirus disease 2019 in California and Washington: prospective cohort study. BMJ. 2020;369:m1923. https://doi.org/10.1136/bmj.m1923.

19. Rees EM, Nightingale ES, Jafari Y, Waterlow N, Clifford S, Pearson CAB, et al. COVID-19 length of hospital stay: a systematic review and data synthesis. medRxiv 2020.04.30.20084780; [cited 2020 July 23]. Available from: https:// www.medrxiv.org/content/10.1101/2020.04.30.20084780v3. DOl: https://doi. org/10.1101/2020.04.30.20084780

20. WHO Working Group on the Clinical Characterisation and Management of COVID-19 infection. A minimal common outcome measure set for COVID19 clinical research. Lancet. 2020[cited 2020 July 23]; Available from: https:// www.thelancet.com/journals/laninf/article/PIIS1473-3099(20)30483-7/ fulltext\#\%20. https://doi.org/10.1016/S1473-3099(20)30483-7.

21. Gorst SL, Altman DG, Blazeby JM, Clarke M, Gargon E, Tunis S, et al. Proceedings of the 5 th meeting of the Core outcome measures in effectiveness trials (COMET) initiative. Trials. 2015;16 Suppl 3(Suppl 3):A1P11. https://doi.org/10.1186/1745-6215-16-s3-a1.

22. Jin X, Pang B, Zhang J, Liu Q, Yang Z, Feng J, et al. Core outcome set for clinical trials on coronavirus disease 2019 (COS-COVID). Engineering (Beijing). 2020. https://doi.org/10.1016/j.eng.2020.03.002.

23. Chen J, Qi T, Liu L, Ling Y, Qian Z, Li T, et al. Clinical progression of patients with COVID-19 in Shanghai, China. J Infect. 2020;80(5):e1-6. https://doi.org/ 10.1016/j.jinf.2020.03.004

24. Wang D, Hu B, Hu C, Zhu F, Liu X, Zhang J, et al. Clinical characteristics of 138 hospitalized patients with 2019 novel coronavirus-infected pneumonia in Wuhan, China. JAMA. 2020;323(11):1061-9. https://doi.org/10.1001/jama. 2020.1585

25. Zelen M. The randomization and stratification of patietns to clinical trials. J Chronic Dis. 1974;27(7-8):365-75. https://doi.org/10.1016/00219681(74)90015-0

26. Srivastava DK, Rai SN, Pan J. Robustness of an odds-ratio test in a stratified group sequential trial with a binary outcome measure. Biom J. 2007;49(3): 351-64.

27. Goyal P, Choi JJ, Pinheiro LC, Schenck EJ, Chen R, Jabri A, et al. Clinical characteristics of Covid-19 in new York City. N Engl J Med. 2020;382(24): 2372-4. https://doi.org/10.1056/NEJMc2010419.

28. Reynolds HR, Adhikari S, Pulgarin C, Troxel AB, Iturrate E, Johnson SB, et al. Renin-angiotensin-aldosterone system inhibitors and risk of Covid-19. N Engl J Med. 2020;382(25):2441-8. https://doi.org/10.1056/NEJMoa2008975.

29. Meng Y, Wu P, Lu W, Liu K, Ma K, Huang L. Sex-specific clinical characteristics and prognosis of coronavirus disease-19 infection in Wuhan, China: a retrospective study of 168 severe patients. PLoS Pathog. 2020;16(4): e1008520. https://doi.org/10.1371/journal.ppat.1008520

30. Jennison C, Turnbull BW. Group sequential methods with applications to clinical trials. Boca Raton: Chapman \& Hall/CRC; 1999

31. East 6 . Statistical software for the design, simulation and monitoring clinical trials. Cambridge: Cytel Inc.; 2016.

32. United States Department of Health and Human Services. Common terminology criteria for adverse events (CTCAE) version 5.0; 2017. Available from: https://ctep.cancer.gov/protocolDevelopment/electronic_applications/ docs/CTCAE_v5_Quick_Reference_8.5x11.pdf. Accessed 5 May 2020.
33. Ingram DD, Kleinman JC. Empirical comparisons of proportional hazards and logistic regression models. Stat Med. 1989;8(5):525-38. https://doi.org/ 10.1002/sim.4780080502.

34. Richardson S, Hirsch JS, Narasimhan M, Crawford JM, McGinn T, Davidson $\mathrm{KW}$, et al. Presenting characteristics, comorbidities, and outcomes among 5700 patients hospitalized with COVID-19 in the new York City area. JAMA. 2020;e206775. https://doi.org/10.1001/jama.2020.6775.

35. R Core Team. R: a language and environment for statistical computing. Vienna: R Foundation for statistical computing; 2018. Available from: https:// www.R-project.org. Accessed 5 May 2020.

36. Li B, Yang J, Zhao F, Zhi L, Wang X, Liu L, et al. Prevalence and impact of cardiovascular metabolic diseases on COVID-19 in China. Clin Res Cardiol. 2020;109(5):531-8.

37. Schett G, Sticherling M, Neurath MF. COVID-19: risk for cytokine targeting in chronic inflammatory diseases? Nat Rev Immunol. 2020;20(5):271-2.

38. Carnethon MR, Pu J, Howard G, Albert MA, Anderson CAM, Bertoni AG, et al Cardiovascular health in African Americans: a scientific statement from the American Heart Association. Circulation. 2017;136(21):e393-423.

39. Brothers RM, Fadel PJ, Keller DM. Racial disparities in cardiovascular disease risk: mechanisms of vascular dysfunction. Am J Physiol Heart Circ Physiol. 2019;317(4):H777-89.

40. Kaiser LD. Dynamic randomization and a randomization model for clinical trials data. Stat Med. 2012;31(29):3858-73. https://doi.org/10.1002/sim.5448.

41. McGonagle D, Sharif K, O'Regan A, Bridgewood C. The role of cytokines including Interleukin-6 in COVID-19 induced pneumonia and macrophage activation syndrome-like disease. Autoimmun Rev. 2020;19(6):102537. https://doi.org/10.1016/j.autrev.2020.102537.

42. Pedersen SF, Ho YC. SARS-CoV-2: a storm is raging. J Clin Invest. 2020;130(5): 2202-5.

43. Zhang Y, Li J, Zhan Y, Wu L, Yu X, Zhang W, et al. Analysis of serum cytokines in patients with severe acute respiratory syndrome. Infect Immun. 2004;72(8):4410-5.

44. Ivanova A, Qaqish BF, Schell MJ. Continuous toxicity monitoring in phase II trials in oncology. Biometrics. 2005;61(2):540-5. https://doi.org/10.1111/j. 1541-0420.2005.00311.x.

45. Song G, Ivanova A. Enrollment and stopping rules for managing toxicity requiring long follow-up in phase II oncology trials. J Biopharm Stat. 2015; 25(6):1206-14. https://doi.org/10.1080/10543406.2015.1086779.

46. Yu J, Hutson AD, Siddiqui AH, Kedron MA. Group sequential control of overall toxicity incidents in clinical trials - non-Bayesian and Bayesian approaches. Stat Methods Med Res. 2016;25(1):64-80. https://doi.org/10. $1177 / 0962280212440535$

47. Ball G. Continuous safety monitoring for randomized controlled clinical trials with blinded treatment information. Part 4: one method. Contemp Clin Trials. 2011;32 Suppl 1:S11-7. https://doi.org/10.1016/j.cct.2011.05.008.

48. Yao B, Zhu L, Jiang Q, Xia HA. Safety monitoring in clinical trials. Pharmaceutics. 2013;5(1):94-106. https://doi.org/10.3390/ pharmaceutics5010094.

49. Ivanova A, Song G, Marchenko O, Moschos S. Moniotring rules for toxicity in phase II oncology trials. Clin Investig. 2015;5(4):373-81.

50. Ray HE, Rai SN. An evaluation of a simon 2-stage phase II clinical trial design incorporating continuous toxicity monitoring. Contemp Clin Trials. 2011; 32(3):428-36.

\section{Publisher's Note}

Springer Nature remains neutral with regard to jurisdictional claims in published maps and institutional affiliations.

\section{Ready to submit your research? Choose BMC and benefit from}

- fast, convenient online submission

- thorough peer review by experienced researchers in your field

- rapid publication on acceptance

- support for research data, including large and complex data types

- gold Open Access which fosters wider collaboration and increased citations

- maximum visibility for your research: over $100 \mathrm{M}$ website views per year

At BMC, research is always in progress.

Learn more biomedcentral.com/submission 